Supplement of Atmos. Meas. Tech. Discuss., 8, 3171-3198, 2015

http://www.atmos-meas-tech-discuss.net/8/3171/2015/

doi:10.5194/amtd-8-3171-2015-supplement

(C) Author(s) 2015. CC Attribution 3.0 License.

(c) (i)

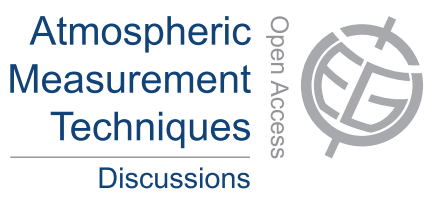

Supplement of

\title{
Measurement of carbonaceous aerosol with different sampling configurations and frequencies
}

\author{
Y. Cheng and K.-B. He \\ Correspondence to: Y. Cheng (ycheng@ mail.tsinghua.edu.cn) and \\ K.-B.He (hekb@tsinghua.edu.cn)
}


Section-1: Evaluation of the activated carbon denuder.

Four factors were considered when evaluating the activated carbon denuder:

(1) Denuder breakthrough and efficiency. Denuder breakthrough, defined as the amount of gaseous organics that are not removed by the denuder and subsequently adsorbed by the filter downstream, was measured by the "breakthrough channel". The "breakthrough channel" was the same as channel 1 in this study, expect that a quartz filter (i.e., the TSP filter; TSP refers to total suspended particulate matter) was placed upstream of the $\mathrm{PM}_{2.5}$ cyclone. In the "breakthrough channel", particles were removed by the TSP filter, and gaseous organics were captured by the charcoal denuder. As a result, OC measured on the quartz filters downstream of the denuder was from breakthrough. In this study, breakthrough OC averaged $0.27 \pm 0.13 \mu \mathrm{gC} / \mathrm{cm}^{2}$, comparable with the filter blank values of OC (averaging $0.43 \pm 0.12 \mu \mathrm{gC} / \mathrm{cm}^{2}$ ). Therefore, the activated carbon denuder used in this study is able to effectively remove the gaseous organics that could be adsorbed by quartz filters (i.e., is able to remove the positive sampling artifact with an efficiency of $100 \%$ ).

(2) Particle loss due to the diffusion to the walls of the denuder. Particle loss can be evaluated by comparing the EC concentrations measured by channel 1 (denuded) and 2 (un-denuded) in this study. EC concentrations ( $24 \mathrm{~h}$ averaged values) measured by these two channels correlated well with a slope of $0.98 \pm 0.01\left(R^{2}=0.91\right)$, while results from the paired-t test suggested that they were not significantly different at a $95 \%$ level of confidence $(2$-tailed $p=0.126)$. Therefore, the particle loss in the denuder was negligible in this study.

(3) Evaporation of particulate OC during passage through the denuder. This effect should be negligible if the residence time of particles in the denuder is less than $0.2 \mathrm{~s}$. In this study, the residence time was $0.18 \mathrm{~s}$, indicating that the evaporation of particulate $\mathrm{OC}$ in the denuder was 
minimal.

(4) Shedding of the denuder material (activated carbon). No tiny charcoal particles were observed on the denuded filters throughout the measurement period. Moreover, results from the $\mathrm{OC} / \mathrm{EC}$ analysis showed that no $\mathrm{EC}$ was detected on the front quartz filter in the breakthrough channel, demonstrating the contamination due to the shedding of the denuder material was negligible. 
Section-2: Problems in the comparison of ATN measured by the carbon analyzer and the filterbased, online instruments.

Although the measurement of ATN by the carbon analyzer is similar to that based on the filterbased, online instruments such as the Aethalometer and the PSAP, ATN retrieved from these two types of techniques should be compared with caution. In the carbon analyzer, the transmittance signal is monitored at only one wavelength, which is 632 and $678 \mathrm{~nm}$ for the DRI and Sunset analyzers, respectively. In the online instruments such as the Aethalometer and the PSAP, the transmittance signal is usually measured at several different wavelengths (a commonly used one is $550 \mathrm{~nm}$ ). Therefore, when comparing ATN retrieved from these two types of techniques, the difference in the measurement wavelength needs to be accounted for, which can be done if the absorption Ångström exponent is known. Moreover, the primary purpose of the carbon analyzer is to determine OC and EC. Thus, compared to the Aethalometer and the PSAP, the filter loading might be much higher when operating the carbon analyzer, indicating that ATN retrieved from the carbon analyzer might be more strongly biased by the artifacts associated with filter loading (e.g., the shadowing effect). 
Section-3: Statistical results for the comparisons, regressions and ratios included in this paper.

Table S-1. Statistical results for the ratios and regressions included in this study.

\begin{tabular}{|c|c|c|c|c|}
\hline Y & $X$ & $\mathrm{Y} / \mathrm{X}$ & Slope & $\mathrm{R}^{2}$ \\
\hline \multicolumn{5}{|c|}{ Performance of the carbon analyzer } \\
\hline TC parallel-1 & TC parallel-2 & $1.00 \pm 0.02$ & $0.99 \pm 0.00$ & 0.99 \\
\hline ATN parallel-1 & ATN parallel-2 & $1.01 \pm 0.07$ & $1.01 \pm 0.02$ & 0.94 \\
\hline $\mathrm{OC}_{\mathrm{T}}$ parallel-1 & $\mathrm{OC}_{\mathrm{T}}$ parallel-2 & $1.00 \pm 0.02$ & $0.99 \pm 0.00$ & 0.99 \\
\hline $\mathrm{EC}_{\mathrm{T}}$ parallel-1 & $\mathrm{EC}_{\mathrm{T}}$ parallel-2 & $1.01 \pm 0.05$ & $1.00 \pm 0.01$ & 0.93 \\
\hline $\mathrm{OC}_{\mathrm{R}}$ parallel-1 & $\mathrm{OC}_{\mathrm{R}}$ parallel-2 & $0.99 \pm 0.03$ & $0.98 \pm 0.01$ & 0.99 \\
\hline $\mathrm{EC}_{\mathrm{R}}$ parallel-1 & $\mathrm{EC}_{\mathrm{R}}$ parallel-2 & $1.01 \pm 0.03$ & $1.02 \pm 0.01$ & 0.99 \\
\hline \multicolumn{5}{|c|}{$\begin{array}{l}\text { Comparison of TC, OC, EC measured by different sampling configurations and frequencies } \\
\text { during the low } R H \text { period }\end{array}$} \\
\hline Low-frequency $\mathrm{TC}_{\mathrm{BQ}}$ & High-frequency $\mathrm{TC}_{\mathrm{DQ}}$ & $1.18 \pm 0.08$ & $1.16 \pm 0.02$ & 0.98 \\
\hline Low-frequency $\mathrm{TC}_{\mathrm{BQ}-\mathrm{QBQ}}$ & High-frequency $\mathrm{TC}_{\mathrm{DQ}}$ & $1.04 \pm 0.07$ & $1.03 \pm 0.02$ & 0.98 \\
\hline High-frequency $\mathrm{TC}_{\mathrm{BQ}}$ & High-frequency $\mathrm{TC}_{\mathrm{DQ}}$ & $1.33 \pm 0.09$ & $1.30 \pm 0.02$ & 0.98 \\
\hline High-frequency $\mathrm{TC}_{\mathrm{BQ}-\mathrm{QBQ}}$ & High-frequency $\mathrm{TC}_{\mathrm{DQ}}$ & $1.16 \pm 0.10$ & $1.13 \pm 0.02$ & 0.97 \\
\hline Low-frequency $\mathrm{OC}_{\mathrm{BQ}}$ & High-frequency $\mathrm{OC}_{\mathrm{DQ}}$ & $1.31 \pm 0.13$ & $1.25 \pm 0.04$ & 0.95 \\
\hline Low-frequency $\mathrm{OC}_{\mathrm{BQ}-\mathrm{QBQ}}$ & High-frequency $\mathrm{OC}_{\mathrm{DQ}}$ & $1.12 \pm 0.11$ & $1.08 \pm 0.02$ & 0.98 \\
\hline High-frequency $\mathrm{OC}_{\mathrm{BQ}}$ & High-frequency $\mathrm{OC}_{\mathrm{DQ}}$ & $1.48 \pm 0.17$ & $1.40 \pm 0.04$ & 0.96 \\
\hline High-frequency $\mathrm{OC}_{\mathrm{BQ}-\mathrm{QBQ}}$ & High-frequency $\mathrm{OC}_{\mathrm{DQ}}$ & $1.23 \pm 0.16$ & $1.17 \pm 0.03$ & 0.96 \\
\hline Low-frequency $\mathrm{EC}_{\mathrm{BQ}}$ & High-frequency $\mathrm{EC}_{\mathrm{DQ}}$ & $0.86 \pm 0.11$ & $0.87 \pm 0.05$ & 0.73 \\
\hline High-frequency $\mathrm{EC}_{\mathrm{BQ}}$ & High-frequency $\mathrm{EC}_{\mathrm{DQ}}$ & $0.99 \pm 0.04$ & $0.99 \pm 0.02$ & 0.95 \\
\hline \multicolumn{5}{|c|}{$\begin{array}{l}\text { Comparison of TC, OC, EC measured by different sampling configurations and frequencies } \\
\text { during the high } R H \text { period }\end{array}$} \\
\hline Low-frequency $\mathrm{TC}_{\mathrm{BQ}}$ & High-frequency $\mathrm{TC}_{\mathrm{DQ}}$ & $0.95 \pm 0.05$ & $0.95 \pm 0.02$ & 0.90 \\
\hline Low-frequency $\mathrm{TC}_{\mathrm{BQ}-\mathrm{QBQ}}$ & High-frequency $\mathrm{TC}_{\mathrm{DQ}}$ & $0.84 \pm 0.05$ & $0.84 \pm 0.02$ & 0.90 \\
\hline High-frequency $\mathrm{TC}_{\mathrm{BQ}}$ & High-frequency $\mathrm{TC}_{\mathrm{DQ}}$ & $1.16 \pm 0.04$ & $1.15 \pm 0.01$ & 0.96 \\
\hline High-frequency $\mathrm{TC}_{\mathrm{BQ}-\mathrm{QBQ}}$ & High-frequency $\mathrm{TC}_{\mathrm{DQ}}$ & $1.04 \pm 0.03$ & $1.04 \pm 0.01$ & 0.97 \\
\hline Low-frequency $\mathrm{OC}_{\mathrm{BQ}}$ & High-frequency $\mathrm{OC}_{\mathrm{DQ}}$ & $0.99 \pm 0.09$ & $0.98 \pm 0.03$ & 0.78 \\
\hline Low-frequency $\mathrm{OC}_{\mathrm{BQ}-\mathrm{QBQ}}$ & High-frequency $\mathrm{OC}_{\mathrm{DQ}}$ & $0.85 \pm 0.08$ & $0.84 \pm 0.03$ & 0.74 \\
\hline High-frequency $\mathrm{OC}_{\mathrm{BQ}}$ & High-frequency $\mathrm{OC}_{\mathrm{DQ}}$ & $1.21 \pm 0.06$ & $1.21 \pm 0.02$ & 0.92 \\
\hline High-frequency $\mathrm{OC}_{\mathrm{BQ}-\mathrm{QBQ}}$ & High-frequency $\mathrm{OC}_{\mathrm{DQ}}$ & $1.07 \pm 0.05$ & $1.07 \pm 0.02$ & 0.93 \\
\hline Low-frequency $\mathrm{EC}_{\mathrm{BQ}}$ & High-frequency $\mathrm{EC}_{\mathrm{DQ}}$ & $0.83 \pm 0.09$ & $0.83 \pm 0.03$ & 0.67 \\
\hline High-frequency $\mathrm{EC}_{\mathrm{BQ}}$ & High-frequency $\mathrm{EC}_{\mathrm{DQ}}$ & $0.96 \pm 0.06$ & $0.96 \pm 0.02$ & 0.81 \\
\hline
\end{tabular}


Table S-1 (continued). Statistical results for the ratios and regressions included in this study.

\begin{tabular}{|l|l|l|l|l|}
\hline $\mathrm{Y}$ & $\mathrm{X}$ & $\mathrm{Y} / \mathrm{X}$ & Slope & $\mathrm{R}^{2}$ \\
\hline \multicolumn{2}{|l|}{ Comparison of ATN measured by different sampling configurations and frequencies } \\
\hline Low-frequency ATN $\mathrm{BQ}_{\mathrm{BQ}}$ & $\begin{array}{l}\text { Integrated high-frequency } \\
\text { ATN }\end{array}$ & $0.89 \pm 0.05$ & $0.89 \pm 0.02$ & 0.93 \\
\hline
\end{tabular}

Tables S-2. The 2-tailed $p$ values for the major comparisons included in this study (2-tailed $p<0.1$ indicates significant difference at a $95 \%$ level of confidence, whereas 2-tailed $p>0.1$ indicates insignificant difference).

\begin{tabular}{|c|c|c|c|}
\hline Y & $\mathrm{X}$ & 2-tailed $p$ & Note \\
\hline RH in the high RH period & RH in the low RH period & 0.000 & Independent t-test \\
\hline $\begin{array}{l}\text { Low-frequency } \mathrm{TC}_{\mathrm{BQ}} \text { during } \\
\text { the high } \mathrm{RH} \text { period }\end{array}$ & $\begin{array}{l}\text { High-frequency } \mathrm{TC}_{\mathrm{DQ}} \text { during } \\
\text { the high } \mathrm{RH} \text { period }\end{array}$ & 0.044 & Paired t-test \\
\hline Low-frequency $\mathrm{EC}_{\mathrm{BQ}}$ & High-frequency $\mathrm{EC}_{\mathrm{DQ}}$ & 0.000 & Paired t-test \\
\hline High-frequency $\mathrm{EC}_{\mathrm{BQ}}$ & High-frequency $\mathrm{EC}_{\mathrm{DQ}}$ & 0.113 & Paired t-test \\
\hline Low-frequency $\mathrm{ATN} \mathrm{N}_{\mathrm{BQ}}$ & $\begin{array}{l}\text { Integrated high-frequency } \\
\text { ATN }_{\mathrm{DQ}}\end{array}$ & 0.000 & Paired t-test \\
\hline $\begin{array}{l}\mathrm{EC}_{\mathrm{R}} \text { to } \mathrm{EC}_{\mathrm{T}} \text { ratios of the low } \\
\text { frequency samples }\end{array}$ & $\begin{array}{l}E C_{R} \text { to } E C_{T} \text { ratios of the high } \\
\text { frequency, denuded samples }\end{array}$ & 0.005 & Independent t-test \\
\hline
\end{tabular}


Section-4: Comparison of the RH data obtained from Weather Underground and from the China Meteorological Data Sharing Service System.

In addition to those from Weather Underground, RH data for Beijing were also available from the China Meteorological Data Sharing Service System (http://cdc.cma.gov.cn/home.do), including daily averaged values measured at three sites: one sub-urban site (site $1 ; 39.8^{\circ} \mathrm{N}, 116.47^{\circ} \mathrm{E}$ ) and two rural sites (site 2 and 3 , located at $40.38^{\circ} \mathrm{N}, 116.87^{\circ} \mathrm{E}$ and $40.45^{\circ} \mathrm{N}, 115.97^{\circ} \mathrm{E}$, respectively). As shown in Figure S-1, RH obtained from these two sources exhibited quite similar daily variations, and particularly, agreed well with respect to the identification of the high RH period.

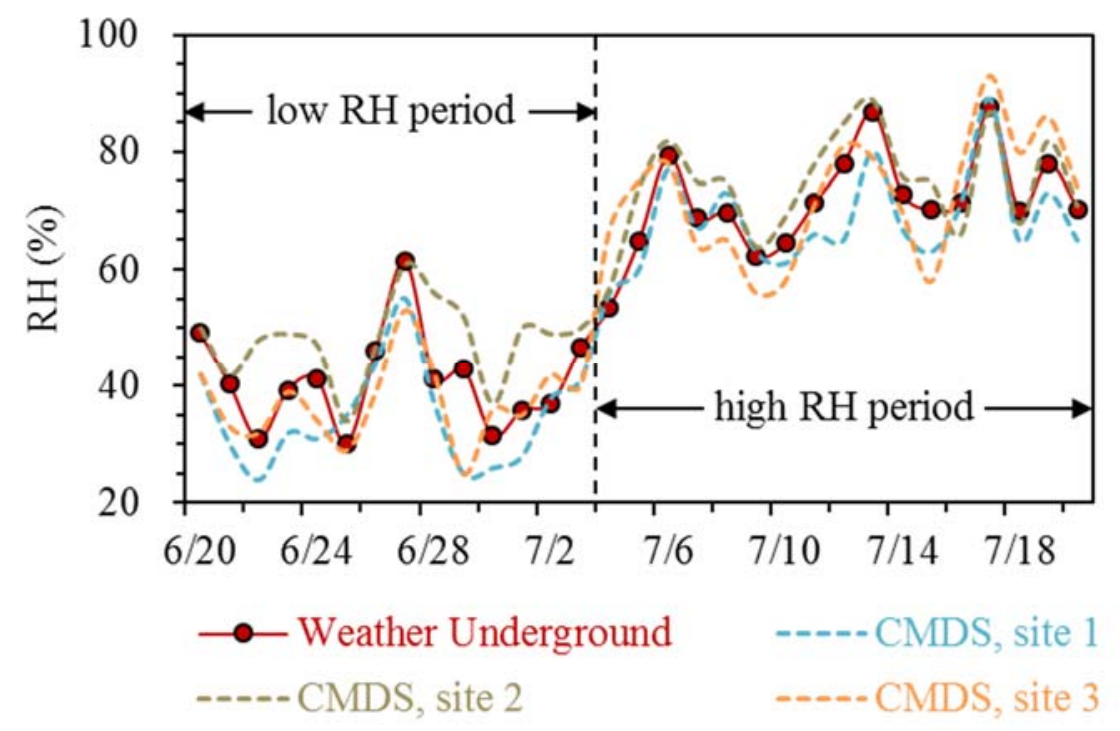

Figure S-1. Daily variations of RH in Beijing during the measurement period of this study. Results from Weather Underground and CMDS (the China Meteorological Data Sharing Service System) are shown separately. 
Section-5: Comparison of TC, OC and EC measured by different sampling configurations and frequencies: scatter plots.
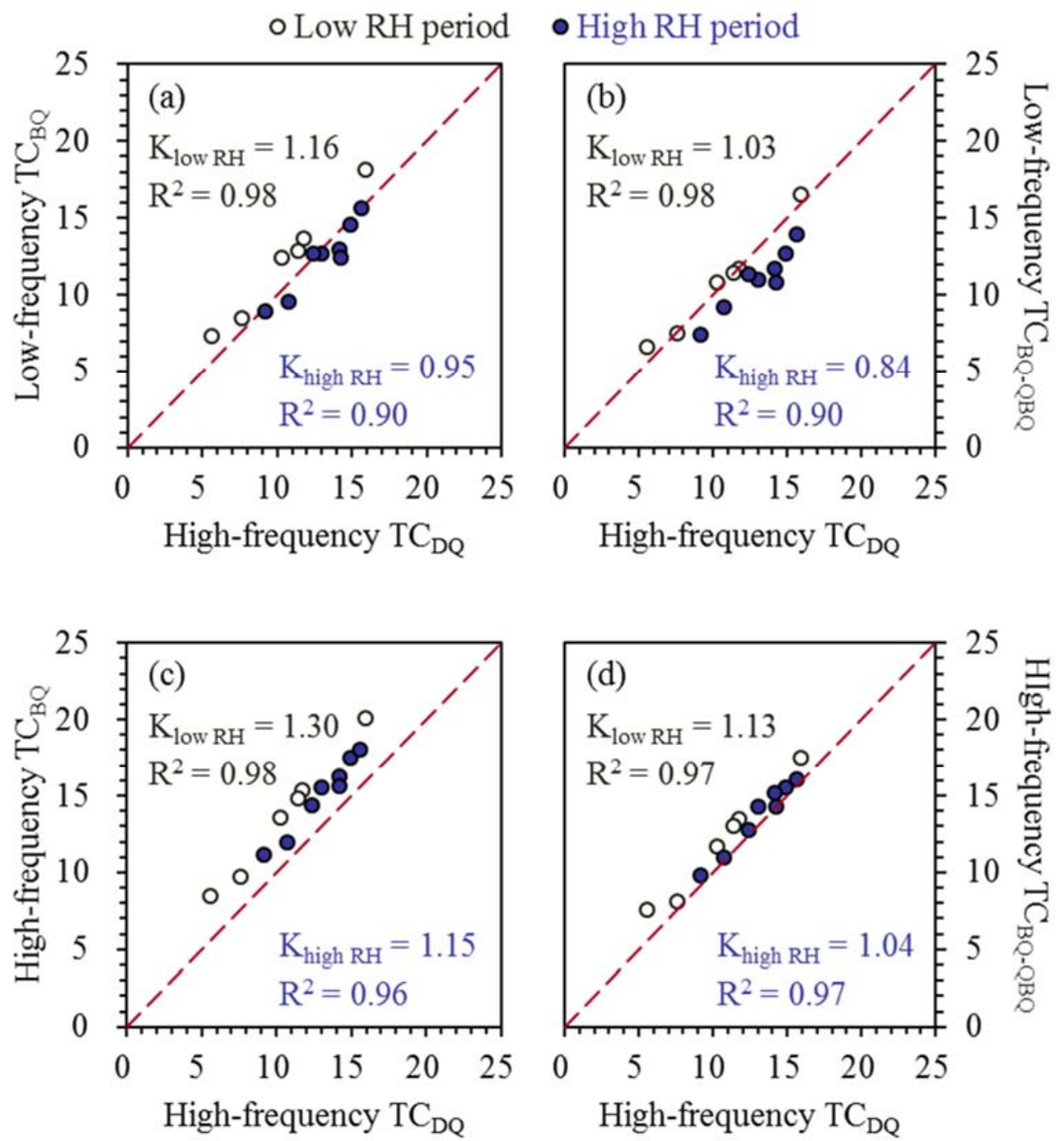

Figure S-2. Comparison of $\mathrm{TC}$ concentrations $\left(\mu \mathrm{gC} / \mathrm{m}^{3}\right)$ measured by different sampling configurations and frequencies. Linear regression results are shown with $\mathrm{K}$ as slope (intercept is set as zero). The dashed lines indicate one-to-one correspondence. 

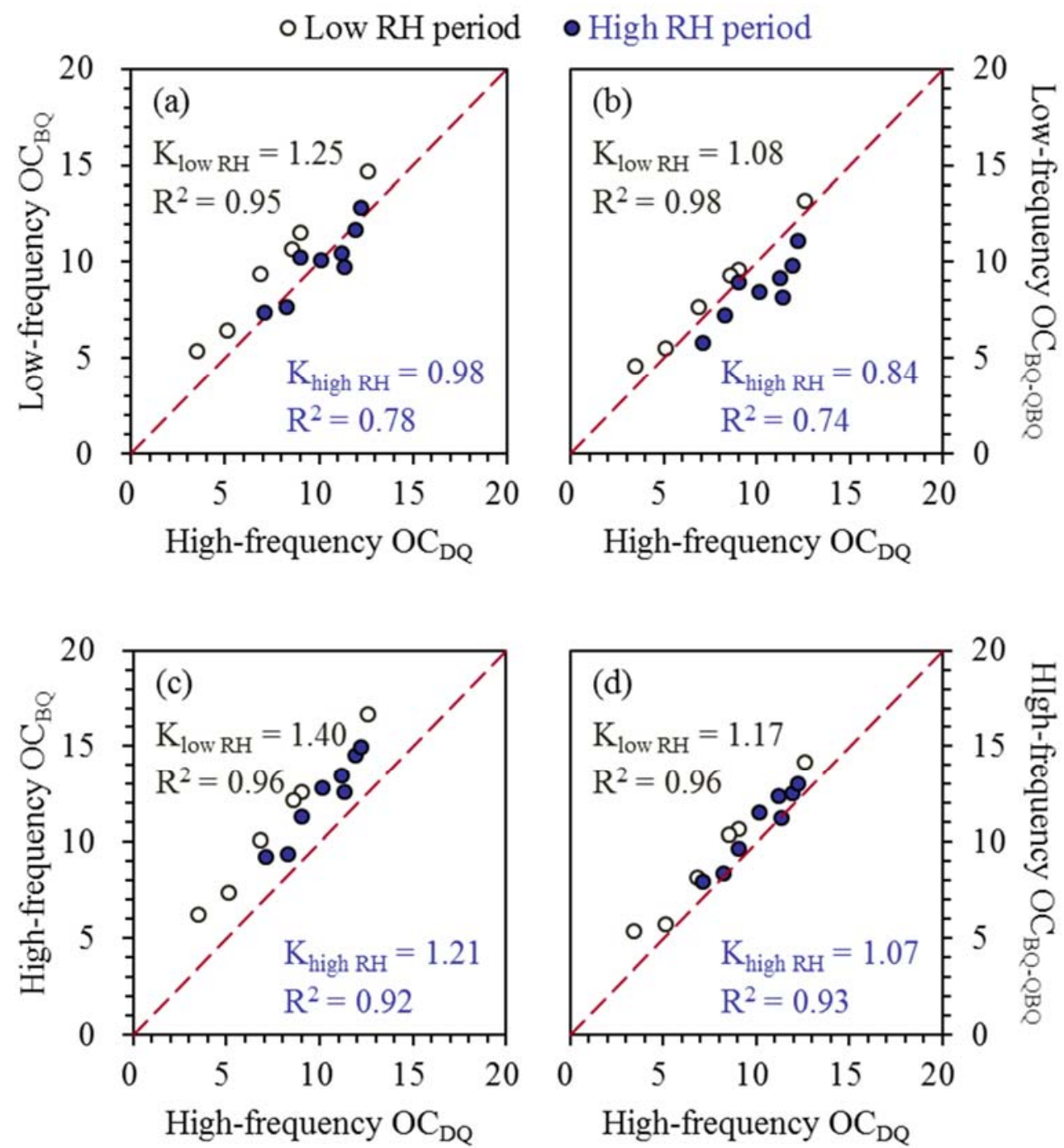

Figure S-3. Comparison of $\mathrm{OC}$ concentrations $\left(\mu \mathrm{gC} / \mathrm{m}^{3}\right)$ measured by different sampling configurations and frequencies. Linear regression results are shown with $\mathrm{K}$ as slope (intercept is set as zero). The dashed lines indicate one-to-one correspondence. 


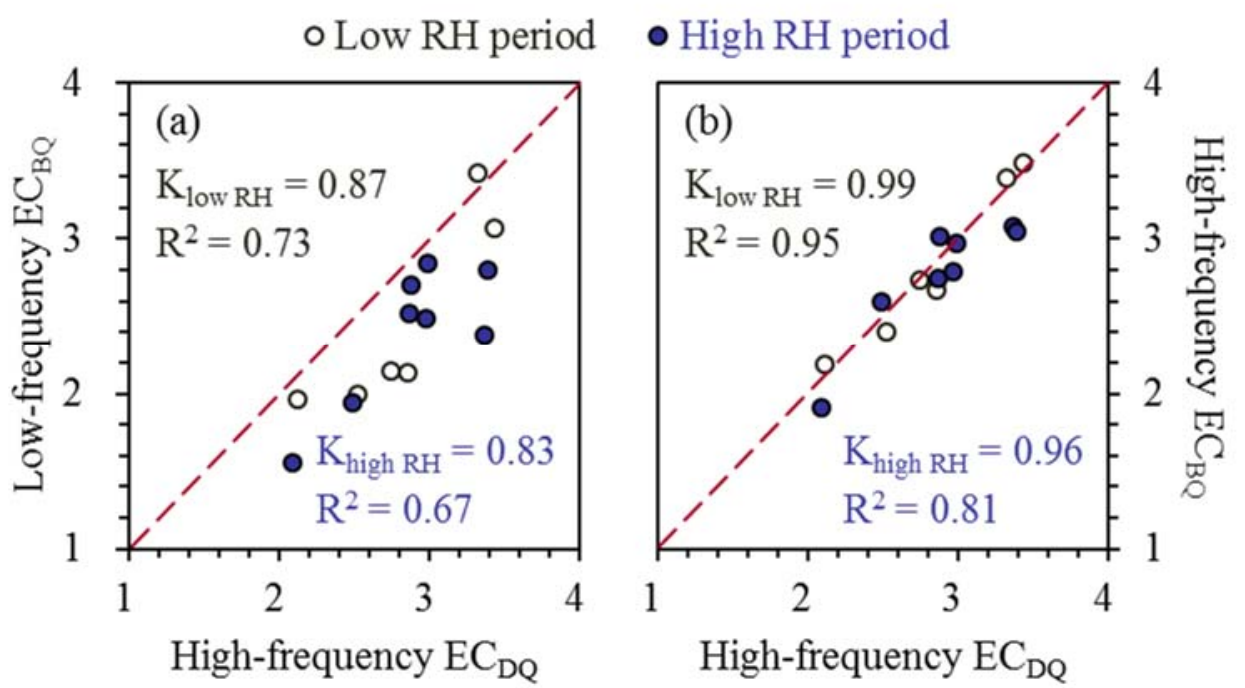

Figure S-4. Comparison of EC concentrations $\left(\mu \mathrm{gC} / \mathrm{m}^{3}\right)$ measured by different sampling configurations and frequencies. Linear regression results are shown with $\mathrm{K}$ as slope (intercept is set as zero). The dashed lines indicate one-to-one correspondence. 